\title{
Physical and psychosocial indicators among office workers from public sector with and without musculoskeletal symptoms
}

\author{
Barbieri, Dechristian França ${ }^{\mathrm{a},{ }^{*}}$; Nogueira, Helen Cristina ${ }^{\mathrm{a}}$; Bergamin, Letícia Januário ${ }^{\mathrm{b}}$ and Oliveira, \\ Ana Beatriz ${ }^{\mathrm{a}, \mathrm{b}}$ \\ ${ }^{a}$ Graduate Program in Physical Therapy, Universidade Federal de São Carlos UFSCar, São Paulo,Brazil \\ ${ }^{\mathrm{b}}$ Undergraduate Program in Physical Therapy, Universidade Federal de São Carlos UFSCar, São Paulo, Brazil
}

\begin{abstract}
Work-related musculoskeletal disorders (WRMD) are the result of the combination of different risk factors. They are very common among computer workers, mainly when neck and upper limbs are considered. Forty-two office workers from a public university participated in this study. They were divided into two groups: Symptomatic Subjects (SS, n=20) and Asymptomatic Subjects (AS, $n=22$ ), according to the Nordic Musculoskeletal Questionnaire (NMQ). Psychosocial indicators were assessed using the Job Content Questionnaire (JCQ) and Utrecht Work Engagement Scale (UWES). Workplaces were evaluated according to the Ergonomic Workplace Analysis (EWA), proposed by the Finnish Institute of Occupational Health. The NMQ showed higher weekly prevalence of complaints on neck, shoulders and wrist $/$ hands $(p=0.00)$ among SS. The annual prevalence of symptoms on wrist/hands was also higher among SS $(p=0.02)$. The JCQ did not show any difference between groups $(p>0.05)$. Higher proportion of servers with 'high level' of engagement, dedication and absorption, according to UWES, was identified among SS $(p<0.01)$. EWA showed worse scores for 'Work Site', 'Job Content' and 'Repetitiveness of the Work' among SS $(p<0.05)$. Servers are exposed to physical and psychosocial risk factors that can contribute to the development of WRMD. Work conditions need to be change in order to improve musculoskeletal health.
\end{abstract}

Keywords: Physical Therapy, ergonomics, computer work, WRMD, psychosocial risk factors

\section{Introduction}

The World Health Organization characterizes work-related musculoskeletal disorders (WRMD) as multifactorial to indicate the inclusion of biomechanical, organizational, psychosocial, and sociological risk factors [10]. Musculoskeletal complaints are very common among computer workers in the modern society, and both show an increasing trend [20]. In general, computer tasks are based on repetitive movements, performed when the worker is seated. Long periods on seated position can increase musculoskeletal complaints when associated to poor ergonomics [24]. Therefore the main musculoskeletal discomforts such as stiffness or pain are more reported in the regions of neck, back, shoulder and wrist [5].

Although WMSDs have been shown to be the result primarily from the biomechanical stressors in- duced by job demands, there is increasing evidence that they may be triggered or worsened by psychosocial work factors. These factors are referred as workers' perceptions or beliefs about the way that their work environment is organized [5,9]. The National Institute of Occupational Health and Safety (NIOSH) has identified five psychosocial factors related to musculoskeletal disorders, i.e., job satisfaction, intensified workload, monotonous work, job control, and social support [3].

Presence of symptoms as aches, pains, sensory change, fatigue, and weakness is often considered as a potential predictor of future WRMDs disorders, and when combined with measures of self-rated health is claimed to be prognostic of future morbidity [15]. Brazil has shown an increase in the demand for health services among workers, with much money being spent with absenteeism and early retire-

* Corresponding author. E-mail: dechristian_fb@live.co.uk 
ments. In 2005 the total cost of these benefits has reached U\$ 170 million [13].

Once psychosocial risk factors are important for the development of WRMD, the public management system, which has particular organizational issues, may impose different risk factors to its workers. According to Filho [11], the awareness of the poor working conditions in the public sector, characterized by insufficient and inadequate equipment, poorly designed space, management practices away from reality and intensification of work as the private sector, has exposed the Brazilian servers to different types of stress.

In order to contribute with information about the Brazilian management system and WRMDs, the objective of this study was to compare physical and psychosocial indicators among office workers from the public sector, characterized as symptomatic and asymptomatic.

\section{Methods}

Forty-two office workers from Federal University of São Carlos (UFSCar), São Carlos, Brazil participated in this study (33 women and 9 men). They were recruited from 23 departments of the University and to be included in the study they should perform, for at least five years, tasks related to office work, such as working on computer at least for 4 hours per day, public attendance and answering the phone. Servers who had been absence from work for a period longer then 1 month in the previous year, and those who have not participated in all assessments were excluded of the study. All servers signed an informed consent form that had been approved by the Ethics Committee of Federal University of São Carlos, Brazil.

Initially the servers were informed about the study and after giving their informed consent, they filled out the Nordic Musculoskeletal Questionnaire (NMQ) [8]. This standardized questionnaire is widely used to measure self-reported musculoskeletal symptoms. Its Brazilian version was published in 2003 [8]. The subjects were instructed to mark the anatomical areas: neck, shoulder, wrists/hands, elbows, upper back and low back if they had trouble (ache, pain, discomfort) during the last 12 months if they have experienced the same symptoms during the previous 7 days. Moreover, the complaints reported for the previous week was accounted for the number of painful body sites. Subjects who have reported any upper limb or neck symptom during the previous week were labelled as "Symptomatic Subjects" (SS: $n=20 ; 16$ women and 4 men, $44.5 \pm 8.0$ years old). Subjects who have not experienced neck or upper limb symptoms during the last 7 days were labelled as "Asymptomatic Subjects" (AS: n=22; 17 women and 5 men, 43.7 \pm 8.2 years old).

The servers also completed the Utrecht Work Engagement Scale (UWES) [25] that proposes the assessment of psychosocial factors by looking at engagement (a positive aspect) instead of measuring burnout. The scale is based on 17 questions: 6 questions evaluate vigor; 5 questions evaluate dedication and 6 questions evaluate absorption. The total score is interpreted as engagement. In order to evaluate the relationship between demand and control, the Job Content Questionnaire (JCQ) was also applied. This scale is also based on 17 questions: 5 questions focusing on demand, 6 questions evaluate control and the other 6 are designated to social support. The Brazilian version of the JCQ was validated by Alves and co-workers [22].

After filling out the questionnaires they were individually assessed through the Ergonomic Workplace Analysis (EWA) protocol, proposed by the Finnish Institute of Occupational Health [17]. The protocol accomplishes 14 items of which 12 were applied (Work site, General physical activity, Work postures and movements, Job content, Job restrictiveness, Worker communication and personal contacts, Decision making, Repetitiveness of the work, Attentiveness, Lighting, Thermal environment, Noise). 'Accident risk' and 'Lifting' were excluded.

\section{Statistical Analysis}

Descriptive statistics was used to describe the prevalence of musculoskeletal symptoms for each body site of NMQ as well as the psychosocial indicators. After this, the results were compared between asymptomatic and symptomatic subjects through Chi-Square (gender, UWES, JCQ and NMQ data) and Man Whitney (age, number of symptomatic body sites, and EWA scores) tests. All analysis were carried out in Statistica Software (v.9.1), considering $\alpha=0.05$. 


\section{Results}

The mean time of daily use of the computer among the servers is $6.4 \pm 0.9$ hours. Both groups had the same age (SS: $44.5 \pm 8.0$ yr; AS: $43.7 \pm 8.2$; $p=0.59$ ) and gender distribution (SS: 16 women and 4 men; SA: 17 women and 5 men; $p=0.90)$. Data of musculoskeletal symptoms (NMQ) showed a higher number of painful body sites in previous 7 days among SS in comparison to AS (SS: $3.25 \pm 1.89$; AS: $0.6 \pm 1.21 ; p=0.00)$. The servers labeled as $\mathrm{SS}$ showed higher prevalence of symptoms than did AS on neck $(p=0.00)$, shoulders $(p=0.00)$, and wrists/hands $(p=0.00)$, when asked about the seven previous days. Although the report of complaints on elbow, low back and knees have also presented higher rates among SS, differences were not significant $(p>0.05)$. The annual prevalence of wrists/hands complaints among SS was significantly higher than among AS $(p=0.02)$ - see Table 1 .

Table 1

Annual and weekly prevalence of musculoskeletal symptoms recorded through NMQ among asymptomatic (AS) and symptomatic (SS) subjects, and statistical comparisons.

\begin{tabular}{|c|c|c|c|c|c|c|}
\hline \multirow{2}{*}{ Body sites } & \multicolumn{3}{|c|}{ Annual Prevalence } & \multicolumn{3}{|c|}{ Weekly Prevalence } \\
\hline & AS (\%) & SS (\%) & $p$-value & AS (\%) & SS (\%) & $p$-value \\
\hline Neck & 40.91 & 65.00 & 0.11 & 0.00 & 55.00 & $0.00 *$ \\
\hline Shoulders & 40.91 & 65.00 & 0.11 & 0.00 & 60.00 & $0.00 *$ \\
\hline Elbows & 13.64 & 15.00 & 0.89 & 0.00 & 15.00 & 0.05 \\
\hline Wrists/hands & 36.36 & 70.00 & $0.02 *$ & 0.00 & 55.00 & $0.00 *$ \\
\hline Upper Back & 50.00 & 60.00 & 0.51 & 13.64 & 35.00 & 0.10 \\
\hline Lower Back & 63.64 & 75.00 & 0.42 & 27.27 & 55.00 & 0.06 \\
\hline Hip/Thighs & 27.27 & 10.00 & 0.15 & 13.64 & 5.00 & 0.34 \\
\hline Knees & 27.27 & 45.00 & 0.23 & 4.55 & 25.00 & 0.05 \\
\hline Ankles/Foot & 31.82 & 50.00 & 0.23 & 9.09 & 20.00 & 0.31 \\
\hline
\end{tabular}

* Chi-Squared test, $\alpha=0.05$

Table 2 presents data of UWES. AS group had more subjects classified with 'high' engagement $(p=0.01)$ when compared with SS group. The AS group also presented more servers classified as 'high' dedication than did SS ( $p=0.01)$. 'Low' dedi- cation was significantly more frequent among SS group ( $p=0.05$ ). Considering the absorption, more servers of AS group were classified as 'high' $(p=0.00)$ while the SS group had more servers classified as 'average' $(p=0.03)$ and 'low' $(p=0.05)$

Table 2

UWES - data among asymptomatic (AS) and symptomatic (SS) subjects, and statistical comparisons.

\begin{tabular}{lcccccccccccc}
\hline \multirow{2}{*}{ Level } & \multicolumn{4}{c}{ Work engagement (\%) } & \multicolumn{3}{c}{ Work vigor (\%) } & \multicolumn{3}{c}{ Work dedication (\%) } & \multicolumn{2}{c}{ Work absorption (\%) } \\
\cline { 2 - 12 } & AS & SS & $\begin{array}{c}\text { p- } \\
\text { value }\end{array}$ & AS & SS & $\begin{array}{c}\text { p- } \\
\text { value }\end{array}$ & AS & SS & $\begin{array}{c}\text { p- } \\
\text { value }\end{array}$ & AS & SS & $\begin{array}{c}\text { p- } \\
\text { value }\end{array}$ \\
\hline Very high & 0.00 & 10.00 & 0.12 & 4.55 & 10.00 & 0.49 & 0.00 & 10.00 & 0.12 & 4.55 & 10.00 & 0.49 \\
High & 54.55 & 15.00 & $0.01^{*}$ & 50.00 & 35.00 & 0.32 & 50.00 & 15.00 & $0.01^{*}$ & 50.00 & 10.00 & $0.00^{*}$ \\
Average & 36.36 & 55.00 & 0.22 & 36.36 & 35.00 & 0.92 & 40.91 & 45.00 & 0.78 & 45.45 & 65.00 & $0.03 *$ \\
Low & 9.09 & 15.00 & 0.55 & 9.09 & 15.00 & 0.55 & 4.55 & 25.00 & $0.05^{*}$ & 0.00 & 15.00 & $0.05^{*}$ \\
Very low & 0.00 & 5.00 & 0.28 & 0.00 & 5.00 & 0.28 & 4.55 & 5.00 & 0.94 & 0.00 & 0.00 & - \\
\hline
\end{tabular}

* Chi-Square test, $\alpha=0.05$

Data of demand, control and social support recorded through JCQ are presented in Table 3. No significant differences were found between groups for JCQ data. Nonetheless, more subjects classified as 'high strain' profile $(p=0.08)$, according to the demand-control model, were seen among SS (see Table 3).

EWA showed worse scores of 'work site' $(p=0.00)$, 'repetitiveness' $(p=0.03)$ and 'work content' $(p=0.00)$ for SS. According to the servers' report the main problems are related to posture restriction due to inadequate workplace layout (seat, view- 
ing, working height, leg space and arm/wrist support), repetitive tasks demand (due to the organiza- tional system), and very low job content (workers perform only simple tasks or part of the entire job).

Table 3

JCQ data among asymptomatic (AS) and symptomatic (SS) subjects, and statistical comparisons.

\begin{tabular}{lcc}
\hline DOMAINS & AS (\%) & SS (\%) \\
\hline Demand & & \\
High & 59.00 & 70.00 \\
Low & 41.00 & 30.00 \\
Control & & \\
High & 72.73 & 60.00 \\
Low & 27.27 & 40.00 \\
Social Support & & \\
High & 72.73 & 55.00 \\
Low & 27.27 & 45.00 \\
Workers' Profile & & \\
Active & 50.00 & 40.00 \\
Passive & 13.64 & 10.00 \\
Low strain & 27.27 & 20.00 \\
High strain & 9.09 & 30.00 \\
\hline * Chi-Squared test, $\alpha=0.05$ & & 0.32 \\
\hline
\end{tabular}

\section{Discussion}

The results presented here showed imported aspects of symptomatic and asymptomatic servers of a public University in Brazil. Once both groups have shown the same characteristics considering age and gender, differences are mainly related to their work and psychossocial features.

SS presented an average of 3.25 painful body sites in the previous week, according to the NMQ. Kristensen et al. [2], who evaluated working conditions of 5.033 office workers in Denmark, reported an average of 1.8 complaints for the previous 7 days among symptomatic workers. Therefore Brazilian servers have shown a high score of musculoskeletal complaints.

The prevalence of symptoms among SS was high on neck $(55 \%)$, shoulders $(60 \%)$, and wrists/hands (55\%). Grifiths et al. [15], who also evaluated musculoskeletal symptoms among 8.000 servers in Australia, reported lower prevalence of symptoms for the same body sites in the previous week: neck $(30 \%)$, shoulders $(28 \%)$, and wrist hands $(22 \%)$. The concentration of symptoms on these body sites is clearly related to the tasks daily performed by the servers. However, the criteria used to define symptomatic and asymptomatic servers were the main responsible for the difference observed between AS and SS. On the other hand, SS had higher prevalence of symptoms on wrists/hands in the previous year than did AS.

The results on work engagement evaluated through UWES have pointed out worse scored for symptomatic servers. A significantly greater number of servers in AS group $(p<0.05)$ were classified with 'high' level for three domains: engagement (SS: 15\% vs AS: $54 \%$ ), dedication (SS: $15 \%$ vs AS: $50 \%$ ) and absorption (SS: $10 \%$ vs AS: $50 \%$ ). Literature reports $[18,21]$ involving 250 employees of a financial institute show similar results for UWES, corroborating the results of this study. According to the same authors, servers need a workplace with organizational support, which allows a work-life balance, resulting in better production and less governmental spending.

The JCQ has shown similar data for SS and AS, with no significant difference between groups. We may assign this result to the fact that the same organizational model is applied to all departments of the university, even tough small management differences can happen among them. Although no significant difference has been found, more servers in SS group presented 'high strain' profile (SS: 30\% vs AS: 9\%). Demerout et al. [6] have associated both low satisfaction and engagement with stressful psychosocial environment. We can suggest that servers evaluated in this study present a similar condition considering data of UWES: low scores of engagement and high strain profile among symptomatic subjects. Coetzer and Rothmann et al. [4] also found job demands (job overload) to be negatively related work engagement.

EWA has shown a large number of work sites with poor ergonomics: inadequate workplace layout and equipment. The job content is compromised by the slow and limited flow of information, which is common in public organizational system. This organizational model generates unstable workflow, with frequent peaks of high demands. In general, servers' 
judgements in EWA indicated low satisfaction with physical and organizational aspects of their workplaces. A low satisfaction with the physical arrangement of the computer workstation and worker perception of their workstation as being poor ergonomics has also been found to be associated with an increased prevalence of pain in the neck and upper extremities in cross-sectional studies [2,12,19].

Literature shows that neck and upper limb regions are more likely to musculoskeletal complaints. This is due to high muscle strain associated with seated position and sustained, low level, muscular contraction [23]. When it is combined with psychosocial strain, the risk for musculoskeletal disorders is higher. Experimental studies using electromyography have demonstrated that increased activation of the trapezius muscle for the neck/shoulder areas occurs when subjects are exposed to psychosocial stressors (such as time pressure) in a standardized computer entry task [16]. Therefore, musculoskeletal symptoms in computers workers are believed to have multifactorial etiology. Non-neutral wrist, arm and neck postures, the workstation design and the duration of computer work as well as psychological and social factors, such as time pressure and high-perceived workload, are believed to interact in the development of these symptoms [26].

Even though we cannot establish a case-effect relationship, statistical differences identified between symptomatic and asymptomatic servers indicate that that physical and psychosocial characteristics can result in musculoskeletal strain. Therefore, the improvement of organizational features combined with better workplace layouts would reduce physical and psychological exposure of servers, resulting in a work-life balance, more effective and productive. Moreover, it would improve quality of life inside and outside workplaces [21].

The improvement of organizational features should be focused on job resources in order to help employees to achieve their work goals - it would reduce job restrictiveness. Other aspects should also be considered, as benefits (e.g., pay, job security), interpersonal and social relations (e.g., supervisor and co-worker support), organization of work (e.g., participation in decision making), and the task (e.g., autonomy, feedback) $[1,7,14]$. According to a metaanalysis performed by Nahrgang et al. [14], the negative work perception is associated with stressful environments, requiring high demand of the worker without enough recovering time.

\section{Limitation of study}

This study has some limitations that must be considered. Initially we need to consider the number of servers evaluated. Differences in psychossocial indicators between SS and AS could arise with the assessment of a larger sample. Additionally, even though all servers do perform office workers, small differences among departments could be seen. Some departments are mostly involved with administrative tasks (financial, purchasing) whilst others are dedicated to the management of undergraduate and graduate courses - which involves dealing with students and professors besides performing regular office work. Moreover, since the sample was based on public servers, the results might not be generalizable to office-based workers of the private sector. Considering the lack of information regarding public systems, further studies need to be performed, including quantitative analysis and exposure assessment in order to support intervention measures to control WRMD in this population.

\section{Conclusion}

Symptomatic and asymptomatic servers have different physical and psychosocial indicators. It indicates that when associated, physical (identified through EWA - worksite, job content, and repetitiveness of the work) and psychosocial risk factors can increase the risk to develop WRMDs. Moreover, physical risk factors can act as negative feedback to psychosocial factors, decreasing engagement and increasing workload.

\section{References}

[1] A.B. Bakker \& E. Demerouti, The job demands-resources model: State of the art. Journal of Managerial Psychology, 2007; 22:309-328.

[2] B.J. Kristensen, K. Sogaard, J. Stroyer, C. Jensen, Computer users' risk factors for developed shoulder, elbow and back symptoms. Scand J Work Environ Health, 2004;30(5):390398.

[3] B.P. Bernard, Musculoskeletal disorders and workplace factors: a critical review of epidemiologic evidence for workrelated musculoskeletal disorders of the neck, upper extremity, and low back. US Department of Health and Human Services CDC (NIOSH), 1997, 97-141.

[4] C.F. Coetzer \& S Rothmann. 'Job demands, job resources and work engagement of employees in a manufacturing organisation'. Southern African Business Review, 2007;11(1):17-32.

[5] D. Sharan, P. Parijat, A.P. Sasidharan, R. Ranganathan, M. Mohandoss and J. Jose, Workstyle Risk Factors for Work Re- 
lated Musculoskeletal Symptoms Among Computer Professionals in India. J Occup Rehabil, 2011, DOI: 10.1007/s10926-011-9294-4.

[6] E. Demerouti, A.B Bakker, The Job Demands-Resources model: Challenges for future research. Journal of Industrial Psychology, 2011; 37(2):1-9.

[7] E. Demerouti, A.B. Bakker, F. Nachreiner, \& W.B. Schaufeli, The job demands-resources model of burnout. Journal of Applied Psychology, 2001;86:499-512.

[8] E.N.C. Barros, N.M.C. Alexandre, Cross-cultural adaptation of the Nordic Musculoskeletal Questionnaire. International Nursing Review, 2003;50:101-108.

[9] G.D. Huang, M. Feuerstein, S.L. Sauter, Occupational stress and work-related upper extremity disorders:concepts and models. Am J Ind Med, 2002;41(5):51-60.

[10] J. Kulin and M. Reaston, "Musculoskeletal disorders early diagnosis: A retrospective study in the occupational medicine setting." J Occup Med Toxicol, 2011; 6(1):1-6.

[11] J. M. J. Filho, Work design and "sick workplace syndrome". A case study in a public institution. Revista Produção, 2004;14(3):058-066.

[12] J. Sillanpaa, S. Huikko, M. Nyberg, P. Kivi, P. Laippala, J. Uitti, Effect of work with visual display units on musculoskeletal disorders in the office environment. Occup Med, 2003;53:443-451.

[13] J.B. Cunha, V.L.G. Blank, A.F. Boing, Time trends of sick leave in Brazilian civil servants (1995-2005). Rev Bras Epidemiol, 2009;12(2):226-236.

[14] J.D. Nahrgang, D.A. Hofmann, F.P. Morgeson, Safety at Work: A Meta-Analytic Investigation of the Link Between Job Demands, Job Resources, Burnout, Engagement, and Safety Outcomes. Journal of Applied Psychology, 2011; 96(1):71-94.

[15] K.L. Grifiths, M.G. Mackey, B.J. Adamson, Behavioral and Psychophysiological Responses to Job Demands and Association with Musculoskeletal Symptoms in Computer Work. J Occup Rehabil, 2011; Doi: 10.1007/s10926-010-9263-3.

[16] L. Birch, B. Jull-Kristensen, C. Jesen, L. Finsen, Acute response to precision, time pressure and mental demand during simulated computer work. Scand J Work Environ Health, 2000;26(4):299-305.

[17] M. Ahonen, M. Launis, Kuorinkat, Ergonomic Workplace Analysis. Ergonomics section finnish institute of Occupational Health. Helsinki, Finland. 1989.
[18] M. Coetzee, M. Villiers, Sources of job stress, work engagement and career orientations of employees in a South African fi nancial institution. Southern African Business Review Volume, 2010;14(1):27-58.

[19] M. Ferreira, H.N. Saldiva, Computer-telephone interactive tasks: predictors of musculoskeletal disorders according to work analysis and workers' perception. Appl Ergon, 2002; 33:147-153.

[20] M. Waersted, N. Hanvold and K.B. Veiersted, Computer work and musculoskeletal disorders of the neck and upper extremity: A systematic review, BMC Musculoskeletal Disorders, 2010;11(79):1-15.

[21] M.D. Lee, P. Hourquet, \& S.M MacDermid, 'Reduced-load work arrangements: the changing nature of professional and managerial work', In Cooper, C.L. \& Burke, R.J. 2002.

[22]M.G.M. Alves, D. Chor, E. Faerstaein, C.S. Lopes, G.L. Werneck, Versão resumida da "job stress scale": adaptação para o português. Revista de Saúde Pública, 2004;38(2):164171

[23] P. Janwantanakul, P. Pensri, V. Jiamjarasrangsri, T. Sinsongsook, Prevalence of self-reported musculoskeletal symptoms among office workers. Occupational Medicine, 2008;58:436438.

[24] P. Janwantanakul, P. Pensri, W. Jiamjarasrangsi, T. Sinsongsook, Associations between prevalence of self-reported musculoskeletal symptoms of the spine and biopsychosocial factors among office workers. J Occup Health, 2009;51(2):114122.

[25] W. Schaufeli, A. Bakker, UWES: Utrecht Work Engament Scale. User's Manual. Occupational Health Psychology Unit, Utrecht University, 2003.

[26] J. Wahlström, Ergonomics, musculoskeletal disorders and computer work. Occupational Medicine, 2005;55:168-176. 